\title{
A raíz del Año Internacional de la Diversidad Biológica
}

A fines de 2006 la Asamblea General de las Naciones Unidas "preocupada por la pérdida continua de la diversidad biológica ..." y “profundamente preocupada por las repercusiones sociales, económicas, ambientales y culturales de la pérdida...y destacando la necesidad de adoptar medidas concretas para invertir esa pérdida" declaró al año 2010 como Año Internacional de la Diversidad Biológica. La actual Lista Roja de la UICN indica que el $36 \%$ de 47978 especies cuyo estado de conservación ha sido evaluado, tiene algún grado de amenaza. Dado este porcentaje y el notorio desbalance entre los niveles de biodiversidad que se pierde y las acciones tendientes a mitigar esta pérdida, la declaración de la Asamblea General resulta oportuna.

Son múltiples las instancias que se deben alcanzar para lograr concretar acciones exitosas en pos de la conservación de la biodiversidad. Entre éstas, merece ser destacada una que normalmente se omite cuando estos pasos se enumeran. Me refiero a la tarea clave que cumplen las revistas científicas, especialmente aquellas que no pertenecen a las grandes casas editoriales, como canales de difusión del conocimiento original sobre la biodiversidad.

Desde su concepción y a lo largo de cinco décadas, GAYANA ha publicado estudios cubriendo distintos aspectos relacionados con la descripción de la biodiversidad y con el entendimiento de los procesos biológicos subyacentes al origen y manutención de la misma. Es así, que en su primer número, GAYANA (serie Gayana Zoológica) publicó un catálogo de los moluscos gasterópodos dulceacuícolas de Chile. El primer taxón nominado y descrito en GAYANA fue uno de categoría específica, Caecum chilense Stuardo 1962, una nueva forma de gasterópodo marino que apareció en el quinto número. En el que aquí se presenta, su septuagésimo cuarto número, GAYANA continúa con su tradición de publicar estudios dirigidos a caracterizar distintos aspectos de la biodiversidad; entre éstos se incluye la descripción de una nueva especie de polilla nocturna y el reporte de registros novedosos de hongos marinos.

Observando la acción desde la periferia de la aldea global, puede ser que las expectativas acerca de los logros tangibles de las actividades enmarcadas y derivadas del Año Internacional de la Diversidad Biológica no sean las más altas. Sin embargo, lo anterior no excluye el que renovemos el compromiso con la tarea de difundir conocimiento original de alta calidad sobre distintos aspectos de la biodiversidad. Vaya esto también como expresión de reconocimiento por parte de GAYANA hacia los investigadores que engalanan nuestras páginas con sus contribuciones.

Guillermo D’Elía

Editor 